This item was submitted to Loughborough's Research Repository by the author.

Items in Figshare are protected by copyright, with all rights reserved, unless otherwise indicated.

\title{
Twisting techniques used in high bar dismounts
}

\section{PLEASE CITE THE PUBLISHED VERSION}

http://journals.humankinetics.com/AcuCustom/SiteName/Documents/Documentltem/10442.pdf

\section{PUBLISHER}

(c) Human Kinetics

\section{VERSION}

AM (Accepted Manuscript)

\section{LICENCE}

CC BY-NC-ND 4.0

\section{REPOSITORY RECORD}

Yeadon, Maurice R., Sung-Cheol Lee, and David G. Kerwin. 2019. "Twisting Techniques Used in High Bar Dismounts". figshare. https://hdl.handle.net/2134/8688. 
This item was submitted to Loughborough's Institutional Repository (https://dspace.lboro.ac.uk/) by the author and is made available under the following Creative Commons Licence conditions.

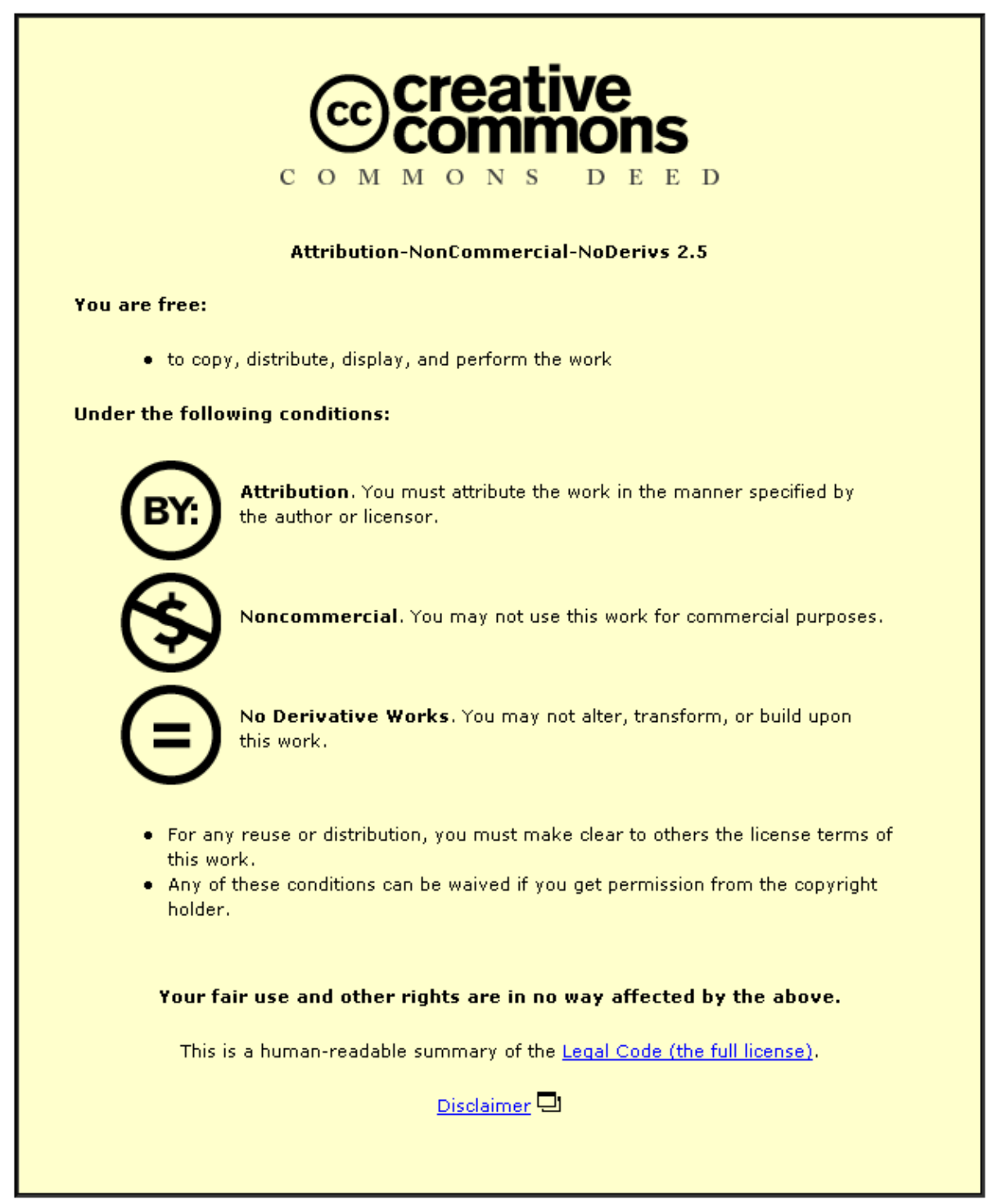

For the full text of this licence, please go to: http://creativecommons.org/licenses/by-nc-nd/2.5/ 


\title{
Twisting Techniques Used in High Bar Dismounts
}

\author{
Maurice R. Yeadon ${ }^{1}$, Sung-Cheol Lee ${ }^{2}$, and David G. Kerwin ${ }^{3}$ \\ ${ }^{1}$ Biomechanics Laboratory, University of Calgary, Calgary, Alberta, Canada T2N 1N4 \\ ${ }^{2}$ Dept. of P.E., Yonsei University, Seoul, South Korea \\ ${ }^{3}$ Biomechanics Laboratory, Loughborough University, Loughborough, LE11 3TU, UK
}

\begin{abstract}
At the 1988 Seoul Olympic Games, eight full twisting somersault dismounts from the high bar were filmed using two cameras during the compulsory exercises of the Men's High Bar competition. Angles describing body configuration and orientation were determined and were input into a computer simulation model of aerial movement. The deviations between simulation and film were less than $2.5^{\circ}$ for tilt angles and less than 0.07 revolutions for twist angles. The twisting techniques employed were quantified using the tilt angle as a measure of twisting potential. Contributions to the maximum tilt angle were determined using simulations based on modifications of the film data. Each of the eight competitors obtained most of the tilt using aerial rather than contact techniques. In general, the majority of the aerial contributions arose from asymmetrical arm and hip movements.
\end{abstract}

\section{Introduction}

Dismounts from the high bar comprise somersaults with or without twist. Twisting somersaults may be categorized according to whether the twist is initiated during contact with the bar or during the aerial phase. This gives rise to the terms contact techniques and aerial techniques for the production of twist. Biesterfeldt (1974) held the opinion that there was little tilt of the body away from the somersault plane and that the twist was produced by continued muscular movements of the gymnast while airborne, in the same way that a cat twists when dropped from an inverted position. Gluck (1979) presented sequences of single somersault dismounts with one, two, and three twists, which showed that the tilt away from the vertical plane after a half somersault increased with the number of twists. This observation is consistent with the use of contact twist, or of aerial twist produced by tilt (Hopper, 1973), but it is not consistent with the use of counterrotation aerial techniques as proposed by Biesterfeldt.

Al-Haroun (1980) filmed six gymnasts performing full twisting somersault dismounts from the rings. It was found that three gymnasts started the twist before releasing first one ring and then the other, while the remaining three released the two rings simultaneously and appeared to initiate the twist after release. A more conclusive result was obtained by Van Gheluwe (1981), who used a six-segment computer simulation model to evaluate filmed performances of three full twisting somersaults from minitramp. By using simulations based on modifications of the film data, it was shown that asymmetrical arm movements during the aerial phase were responsible for most of the twist.

A method of partitioning twist contributions was developed by Yeadon and Dunn (1987), who used the angle of tilt as a measure of twisting. By using an 11-segment simulation model it was shown that for eight twisting somersaults from the 1-meter springboard, the majority of the tilt arose from asymmetrical movements during the aerial phase.

The twisting techniques used by gymnasts may depend upon the type of dismount and the level of expertise. In this study the full twisting dismounts of the compulsory high bar exercises as performed by the best of the Olympic competitors will be analyzed to determine the contributions of contact and aerial techniques. 


\section{Methods}

\section{Data Collection}

The compulsory high bar exercises of the Men's Olympic Gymnastics competition at the 1988 Seoul Olympic Games were filmed using two Photosonics 1PL 16-mm cine cameras. The cameras were placed at the rear of the tiered seating areas, giving front and side views of the dismounts. The camera locations and two points on one of the vertical supports of the high bar were surveyed for later use in the camera calibration. Cameras were operated at nominal framing rates of $70 \mathrm{fps}$, providing approximately 90 frames for the aerial phase of each dismount.

Prior to the competition, 35-mm slides were taken of the seven members of the Canadian Team to give front and side views from which anthropometric data could be obtained on a variety of gymnast physiques for the purpose of calculating segmental inertia parameters.

\section{Data Analysis}

Six of the eight finalists in the high bar competition were selected for analysis. The film records of the other two were incomplete and were replaced by sequences of the two competitors who showed the best dismounts of the remaining gymnasts with a score of 9.8 or above in the compulsory exercise. This resulted in one competitor each from Canada, Japan, Rumania and the USSR, and two competitors each from East Germany and China.

The front and side views of the aerial phase of each dismount were digitized. The corners of the projected film frame were each digitized four times and their mean coordinate values were taken to give the center of the film frame so that the orientation of the principal axis of the camera lens could be determined. The images of the upper and lower points on one of the vertical supports of the high bar were each digitized 16 times and mean coordinate values were obtained. The camera calibration was carried out using the surveyed three-dimensional locations of the front camera, side camera, and the two reference points on the high bar together with the digitized coordinates of the film frame centers and the two reference points (Yeadon, 1989).

In each film frame of the aerial phase, the wrist, elbow, shoulder, hip, knee, and ankle centers were digitized, resulting in a total of 12 landmarks. Since the field of view was about 8 meters wide, the image of each gymnast was relatively small. As a consequence it was difficult to reliably identify landmarks that would give the orientations of the head, hands, and feet. These body segments were assumed to maintain fixed orientations relative to their adjacent segments. The head was taken to be in normal alignment, the hands extended, and the feet plantarflexed.

The film taken by each camera was digitized twice to facilitate error correction and to produce error estimates for use in curve-fitting the coordinate data using the quintic spline of Wood and Jennings (1979). The two digitizations of the two film sequences produced four combinations of data from which four estimates of the three-dimensional locations of the landmarks could be derived. The digitized data sets from the two cameras were synchronized by matching the paths traced by the center of mass of the body close to takeoff and landing (Yeadon, 1989). The quintic spline fits to the displacement data were then used to obtain synchronous data sets.

The body was modeled using four arm segments, four leg segments, and three torso segments. The orientation of the body was defined by angles corresponding to somersault, tilt, and twist while body configuration was specified using 14 angles to describe the relative orientations of the body segments. Three angles were used at each shoulder and one angle at each elbow. One angle was used to describe flexion at both hips and another angle to describe flexion at both knees. These assumptions of symmetry are consistent with the requirements of good form in twisting somersaults. Two thigh abduction angles were used. The remaining two angles gave the orientation of the upper torso segment while the orientation of the midtorso segment relative to the pelvis was assumed to be a function of the orientations of the thighs relative to the pelvis (Yeadon, 1990c). Such an assumption is necessary since there are no points on the torso other than the hip and shoulder centers that can be identified reliably.

The three-dimensional coordinates of the digitized joint centers were reconstructed from each of the four combinations of synchronous data using the midpoint of the common perpendicular to the rays from the two cameras (Yeadon, 1989). Four estimates of each orientation angle were determined and quintic splines were fitted to the mean values so that derivatives could be obtained (Yeadon, 1990a). 
Anthropometric measurements were obtained by digitizing the front and side views of the 35-mm film of the Canadian Team members that had been taken prior to the competition. Segmental masses, mass center locations, link lengths, and moments of inertia were determined using a mathematical inertia model of the human body (Yeadon, 1990b).

An 11-segment model of the body was used to determine the angular momentum about the whole body mass center during the dismount for each of the seven sets of segmental inertia parameters, using the time histories of the 17 orientation angles (Yeadon, 1990c). The mean values of the calculated angular momentum components and the time histories of the 14 configurational angles were used as input to an 11-segment simulation model of aerial movement (Yeadon, Atha. \& Hales, 1990). The segmental inertia set for each competitor was selected to be that which produced the closest agreement between the twist values obtained from simulation and film.

The angle of tilt between the longitudinal axis of the body (corresponding to minimum moment of inertia) and the invariable plane perpendicular to the angular momentum vector is approximately proportional to the rate of twisting for a given body configuration (Yeadon, 1984). The angle of tilt may therefore be used as a measure of the twisting potential, independent of the actual configuration adopted. The value of the tilt angle when the hands released the bar was determined. This initial tilt angle is a measure of the contribution of the twist initiated during contact with the bar. The subsequent increase in the tilt angle during the dismount gives the contribution of aerial twisting techniques to the maximum tilt obtained.

In order to partition the tilt produced in the aerial phase into contributions associated with configurational symmetry and asymmetries of arms, chest, and hips, the configurational angles obtained from film were modified. These modifi- cations comprised the systematic removal of asymmetries of the arms, chest, and hips about the sagittal plane. The tilt angle produced at the time corresponding to maximum tilt in the original movement was determined from simulations based upon the modified configurations and the contributions of body symmetry, and arm, chest, and hip asymmetries were calculated from these values (Yeadon \& Dunn, 1987).

\section{Results and Discussion}

Estimates of the accuracy of the synchronization of the two camera views were obtained by taking the difference between the values obtained from the two digitizations.

These error estimates of the synchronization were all less than $0.003 \mathrm{~s}$. Mean error estimates of the accuracy of repeated digitization were found to lie between $0.009 \mathrm{~m}$ and $0.012 \mathrm{~m}$. The difference between the values of the orientation angles obtained from simulation and film were evaluated at the time for which the film value of the tilt angle was maximum. Typically this occurred at around the half-twist position. Somersault errors ranged from 0.00 to 0.02 revolutions, twist errors ranged from 0.00 to 0.07 revolutions, and tilt errors from $0.1^{\circ}$ to $2.5^{\circ}$. Figure 1 compares a filmed movement with the corresponding computer simulation using computer graphics.

Table 1 presents the contributions made to the maximum tilt angle in each of the eight dismounts. The initial tilt angle is the angle between the longitudinal axis and the invariable plane perpendicular to the angular momentum vector at the moment of bar release. This initial value is a measure of the contribution that contact techniques make to the total tilt. The symmetry contribution indicates how much the tilt angle increases from its initial value during a simulation that enforces symmetry of the arms, chest, and hips about the sagittal plane. This increase may be due to nutation or may arise from a symmetrical configuration change. Nutation is an oscillation of the tilt angle that occurs when the whole-body principal moments of inertia are all distinct (Yeadon, 1986). Such nutation is large when the arms are held wide so that the difference between the maximum and intermediate principal moments is great. The typical symmetrical movement that produces tilt is a lowering of the arms parallel to the sagittal plane at the quarter-twist position. The contributions listed under arms, chest, and hips arise from asymmetrical arm movements, torsion of the chest, and lateral flexion at the hips.

For each of the eight dismounts analyzed, the sum of the tilt contributions (as listed under "total") was within $0.6^{\circ}$ of the tilt value obtained from the unmodified simulation. It should be noted that the values in Table 1 have been rounded to the nearest degree so that the value under the "total" heading is not always exactly the same as the sum of the stated individual values.

Each of the eight gymnasts produced more tilt in the aerial phase than in the contact phase. Contact 

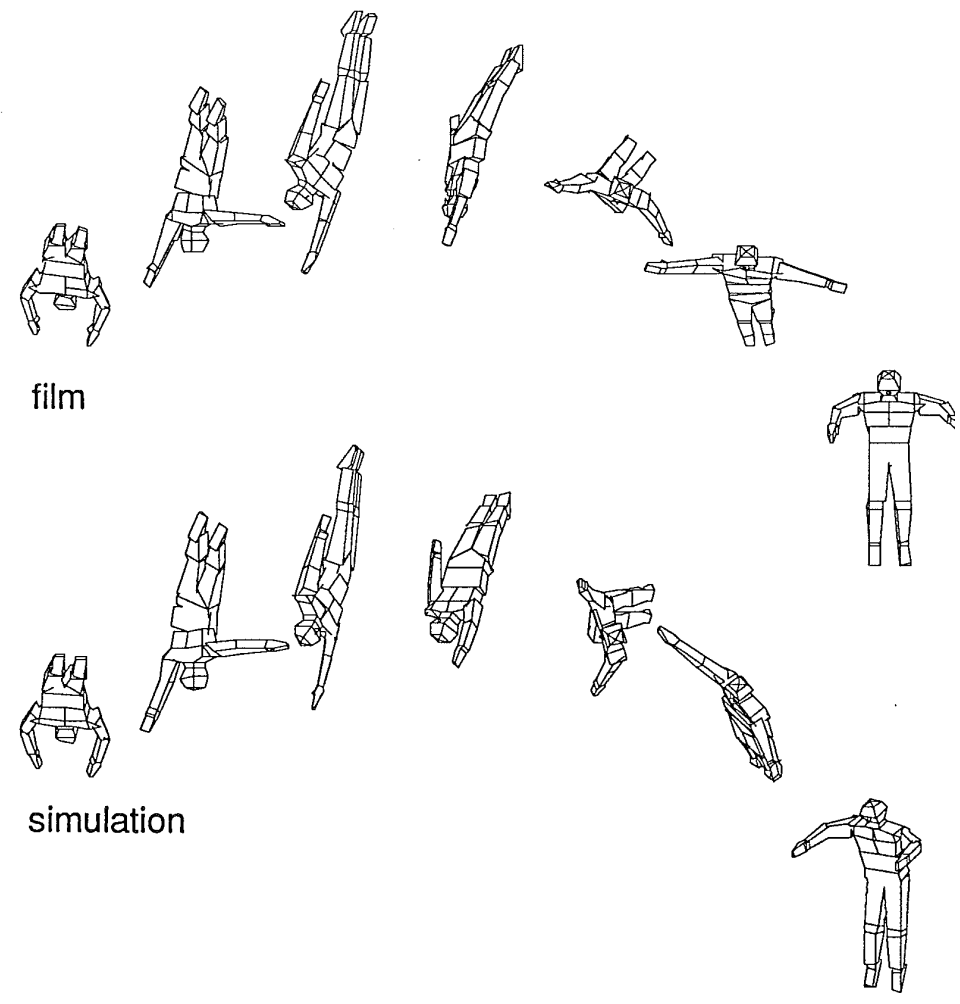

Figure 1: Comparison of film and simulation sequences for Competitor 121.

contributions ranged from $-1^{\circ}$ to $5^{\circ}$, while aerial contributions ranged from $5^{\circ}$ to $17^{\circ}$. Symmetrical contributions accounted for $0^{\circ}$ to $6^{\circ}$ of tilt. Asymmetrical arm movements produced from $1^{\circ}$ to $9^{\circ}$, chest torsion from $0^{\circ}$ to $3^{\circ}$, and asymmetrical hip movement from $1^{\circ}$ to $9^{\circ}$.

Table 1: Tilt Contributions for Eight Full Twisting Somersaults

\begin{tabular}{|c|c|c|c|c|c|c|}
\hline \multirow{2}{*}{ Competitor } & \multicolumn{7}{|c|}{ Tilt contribution in degrees } \\
\cline { 2 - 7 } & Initial & Symmetry & Arms & Chest & Hips & Total \\
\hline 112 & 5 & 6 & 2 & 1 & 4 & 18 \\
\hline 121 & 1 & 1 & 9 & 2 & 2 & 15 \\
\hline 122 & 1 & 3 & 9 & 1 & 3 & 16 \\
\hline 143 & 5 & 2 & 6 & 1 & 4 & 17 \\
\hline 149 & 0 & 0 & 9 & 0 & 9 & 17 \\
\hline 170 & -1 & 1 & 6 & 1 & 6 & 14 \\
\hline 179 & 1 & 1 & 5 & 3 & 7 & 17 \\
\hline 189 & 4 & 3 & 1 & 1 & 1 & 9 \\
\hline mean & 2 & 2 & 6 & 1 & 4 & 15 \\
\hline
\end{tabular}

Figure 2 shows graphics sequences of Competitors 112 and 189, who had contact contributions of $5^{\circ}$ and $4^{\circ}$, respectively. The effect of the contact twist is evident in the first image of each sequence, which shows that the body had already twisted at takeoff. Both competitors lowered their arms at around the quarter-twist position, increasing the tilt angle above the initial value. This symmetrical contribution was large for Competitor 112, who moved straight arms through a large angle, but it was smaller for Competitor 189, who moved bent arms through a small angle.

Figure 3 shows graphics sequences of Competitors 121 and 149, who had large contributions from asymmetrical arm movements. Competitor 121 lowered his left arm to produce the tilt, resulting in twist 

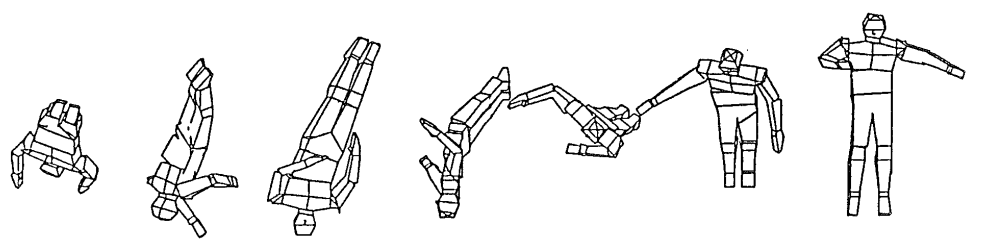

189
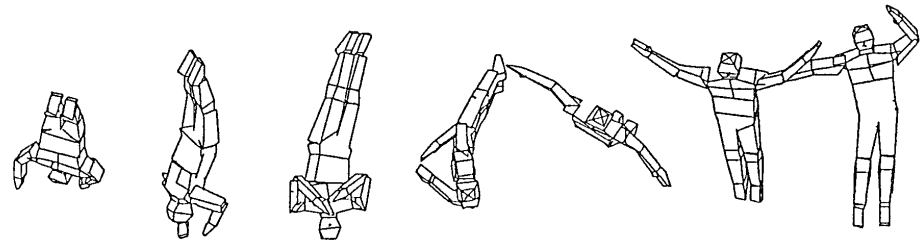

Figure 2: Graphics sequences of the dismounts of Competitors 112 and 189.

121

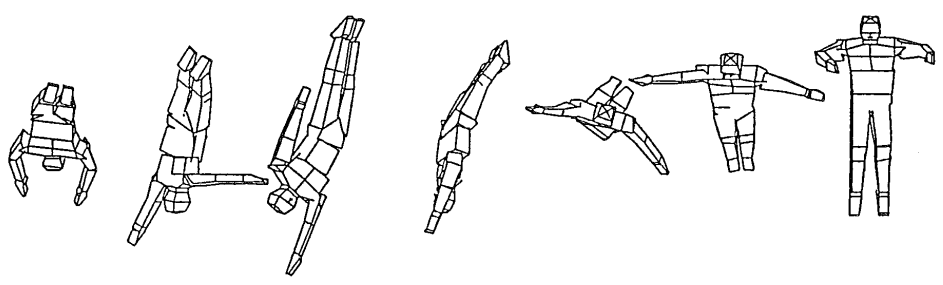

149
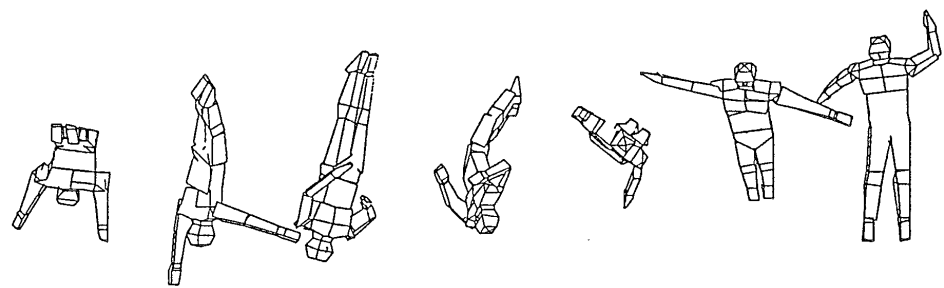

Figure 3: Graphics sequences of the dismounts of Competitors 121 and 149. 
to the left, and maintained arm asymmetry throughout the twisting phase, permitting him to remove the tilt prior to landing by reversing the original arm movement. Competitor 149 lowered first the left arm and then the right arm and was not as successful in removing the tilt prior to landing. From Table 1 it can be seen that Competitor 149 obtained $9^{\circ}$ of tilt by flexing laterally at the hips before extending at a quarter twist. In contrast. Competitor 121 produced only $2^{\circ}$ of tilt using asymmetrical hip flexion. From Figure 3 it can be seen that Competitor 121 still had lateral flexion at the half-twist position, and as a consequence had a small hip contribution since the body should have been extended by the quarter-twist position in order to produce additional tilt (Yeadon \& Atha, 1985).

Since all eight of these elite gymnasts used aerial techniques rather than contact techniques in producing the twist, it might be speculated that there is some advantage in using aerial techniques or some disadvantage in using contact techniques. One advantage of using aerial techniques is that the release from the bar may be made in exactly the same way as for a straight somersault dismount. This means that the learning of the full twist may be based upon modifying only the aerial phase of a known skill. One disadvantage of using contact techniques is that the angular momentum vector is not horizontal and so, if the tilt is removed to stop the twist, a vertical landing cannot be made whereas if a vertical landing is made the gymnast will still be twisting. This problem increases with the magnitude of the initial tilt angle. If gymnasts limit the magnitude of the initial tilt angle in order to reduce this effect, it might be expected that the additional tilt required for single somersault dismounts with two or three twists will be obtained using aerial techniques.

\section{References}

Al-Haroun, M.R. (1980). Three dimensional cinematographic analysis of selected full twisting movements in gymnastics. Doctoral dissertation, Indiana University.

Biesterfeldt, H.J. (1974). Twisting mechanics II, Gymnast. 16, 6-7, 46-47.

Gluck, M. (1979). So you want to twist: Part I. Ontario Gymnast, 31, 14-20.

Hooper, B.J. (1973). The mechanics of human movement. London: Crosby Lockwood Staples.

Van Gheluwe, B. (1981). A biomechanical simulation model for airborne twist in backward somersaults. Journal of Human Movement Studies. 7, 1-22.

Wood, G.A,, \& Jennings, L.S. (1979). On the use of spline functions for data smoothing. Journal of Biomechanics. 12, 477-479.

Yeadon, M.R. (1984). The mechanics of twisting somersaults. Doctoral dissertation, Loughborough University.

Yeadon, M.R. (1986). The biomechanics of twisting somersaults. In Proceedings of the North American Conference on Biomechanics (pp. 33-34). Montreal: Canadian Society for Biomechanics.

Yeadon, M.R. (1989). A method for obtaining three-dimensional data on ski jumping using pan and tilt cameras. International Journal of Sport Biomechanics. 5, 238-247.

Yeadon, M.R. (1990a). The simulation of aerial movement. Part I: The determination of orientation angles from film data. Journal of Biomechanics. 23, 59-66.

Yeadon, M.R. (1990b). The simulation of aerial movement. Part II: A mathematical inertia model of the human body. Journal of Biomechanics, 23, 67-74.

Yeadon, M.R. (1990c). The simulation of aerial movement. Part III: The determination of the angular momentum of the human body. Journal of Biomechanics. 23, 75-83. 
Yeadon, M.R., \& Atha, J. (1985). The production of a sustained aerial twist during a somersault without the use of asymmetrical arm action. In D.A. Winter, R.W. Norman, R.P. Wells, K.C. Hayes, \& A.E. Patla (Eds.), Biomechanics IX B (pp. 395-400). Champaign, IL: Human Kinetics,

Yeadon, M.R., Atha, J., \& Hales, F.D. (1990). The simulation of aerial movement. Part IV: A computer simulation model. Journal of Biomechanics. 23, 85-89.

Yeadon, M.R., \& Dunn, E.G. (1987). A method for determining the contributions of aerial twisting techniques to performances of twisting somersaults. In Proceedings of the 11th Annual Meeting of the American Society of Biomechanics (pp. 161-162). Davis: American Society of Biomechanics.

\section{Acknowledgment}

The support provided by the International Olympic Committee Medical Commission and the Sport Canada Applied Research Program is gratefully acknowledged. 